\title{
Synthesis and Characterization of Ion Exchanger Based on Waste Cotton for Dye Removal from Wastewater
}

\author{
A.I. Waly' ${ }^{1}$ M.A. Khedr' ${ }^{2}$ H.M. Ali ${ }^{*}$ and B.Y. Riad ${ }^{3}$, I.M. Ahmed ${ }^{2}$ \\ ${ }^{1}$ Preparingand Finishing Department, National Research Centre, Cairo, Egypt. \\ ${ }^{2}$ Chemical Engineering Department, National Research Centre, Cairo, Egypt. \\ ${ }^{3}$ Chemistry Department, Faculty of Science, Cairo University, Egypt.
}

\begin{abstract}
ILYCIDYL methacrylate (GMA) polymerization with waste cotton fabric by utilizing a
$\checkmark$ co-initiator of ferrous cellulose thiocarbonate-hydrogen peroxide redox system was first studied under various conditions. These include the polymerization time, temperature, liquor ratio, $\mathrm{pH}$ and concentrations of the initiator and monomer. The product cellulose-poly(glycidyl methacrylate) graft copolymer (CPGMA) produced at best polymerization conditions was then functionalized with triethylammonium chloride (TEAC), aiming to obtain a low-cost adsorbent for dye removal from wastewater. Also, factors that affecting the amination reaction, which include; reaction time, temperature, liquor ratio, $\mathrm{pH}$, and aminating agent/epoxy molar ratio were studied. The prepared amino-functionalized cellulose-poly(glycidyl methacrylate) graft copolymer (AM-CPGMA) was further characterized by the FT-IR, thermal gravimetric analysis (TGA) and surface area measurement based on Brunauer-Emmett-Teller (BET) and Barrett-Joyner-Halenda (BJH) theories. The dye adsorption capacity of the anion exchanger was also evaluated.
\end{abstract}

Keywords: Cotton fibers, Glycidyl methacrylate, Graft copolymerization, Aminization.

\section{Introduction}

Various industries such as paper and pulp manufacturing, plastics, textile, leather treatment and printing consuming large amounts of synthetic chemical dyes. Annually, more than 100,000 commercial dyes exist and over 7 $\mathrm{x} 10^{5}$ ton are produced worldwide [1]. Most of these dyes are un-biodegradable [2]. According to recent researches, about $12 \%$ of synthetic dyes are wasted during manufacturing and processing operations that leads to release of dyes contaminated effluents into environment [3]. Among various industries, textile industry ratings first in the consumption of dyes for coloring fiber. Dyeing industry is one of the largest water consuming industries. Discharge of dyes into water bodies maybe toxic to an aquatic life and can cause serious harm to human beings [4]. Accordingly, elimination of dyes from industrial effluents is recognized as an environmental challenge and polity legislation imposes treatment of textile wastewater. However, the treatment of dyed wastewater is very difficult because they are highly variable in composition [5], soluble in water, resistant to aerobic digestion, and are stable to light, heat, and oxidizing agents [6]. Hence there is an endless need to have an efficient process that can remove these dyes effectively [7].

In the last years, different methods have been applied for the treatment of wastewater containing dyessuch as: chemical coagulation/flocculation, chemical precipitation, electrochemical degradation [8], reverse osmosis, nano-filtration, ultra-filtration [9], electrochemical combined treatments [10], photo-catalytic degradation using UV/TiO [11], Fenton biological treatment scheme [12].

Further, amongst treatment techniques, adsorption is distinguished as a method for treating of aqueous effluent. It have several advantages like possibility of low cost regeneration, known process equipment availability, sludge-free operation and sorbets recovery [13]. Due to the various merits of activated carbon that include high surface area, micro-pore structures, high adsorption capacity and high degree of surface reactivity. It is largely used as dye adsorbent. However, commercially available activated carbon suffers of low mechanical properties, expensive and has high regeneration cost [14].

*Corresponding author e-mail: hanaamohamedaly2007@gmail.com

DOI: 10.21608/EJCHEM.2018.4885.1435

C2017 National Information and Documentation Center (NIDOC) 
Because of their variety in surface and porosity, high physical-chemistry stability, regeneration and reuse for continuous process, polymeric adsorbents have been used for the removal and recovery of organic pollutants from industrial wastewater. Nevertheless, finding new absorbents for dyes removal, with high adsorption capacities is still a challenge.

Agricultural waste-based adsorbents are a low cost, widespread, biodegradable, non-toxic, and have strong affinity for some selected dyes. However, these substances in their raw state have low efficiency, and consequently, further chemical modification by graft polymerization with vinyl monomers is an efficient method for improving the adsorption performance of a polymeric adsorbent [15].

This approach of chemical modification leads to more suitable, highly efficient, and cheap ion exchangers particularly from the agricultural waste materials. Cellulose materials are considered as good substrates for water pollutants elimination. This is based on its plenty, natural friendly polymer and its chemical and physical properties [16]. It can be manufactured in many different shapes, powders, grains, yarns, woven and nonwoven fabrics. Also, different materials can prepared from it for any kind of application. One monomer widely used is glycidyl methacrylate (GMA). It has at one end a double bond, cana ttach carbon centered radicals, and at the other end an epoxy group that can be utilized for further chemical modifications.

The merits of GMA over other monomers are distinguished by the fact that, it is nontoxic, uncontaminated, inexpensive, and highly reactive due to presence of epoxy group, which withdraws electron towards the second carbon atom of the double bond, and hence, facilitate its cleavage at the free radical initiation reaction. Also this group can be opened with many agents to give either anion or cation exchangers. For instance, action exchange adsorbent based on cellulosic fabric wastes carrying sulfonic acid group was synthesized by graft polymerization of glycidyl methacrylate (GMA) with consequent chemical modification of the epoxy groups with sodium sulfite $/ \mathrm{H}_{2} \mathrm{SO}_{4}$ [17]. It is demonstrated that at $\mathrm{pH}=$ 5 , the Co (II) ions ultimate adsorption capacity was $91 \%$.

On the other hand, a cellulose-based anion exchanger was prepared through graft copolymerization of glycidyl methacrylate onto cellulose in the presence of $\mathrm{N}$, $\mathrm{N}^{\prime}$ methylenebisacrylamideas a cross-linker followed by amination using dimethylamine and hydrochloric acid quaternization [18]. The vanadium adsorption process achieved more than $99.6 \% \mathrm{~V}^{-5}$ removal from an initial concentration of $25.0 \mathrm{mg} / \mathrm{L}$.

The present work is concerned with the synthesis of a resin-bound quaternary ammonium salt, based on cotton waste fibers grafted with GMA monomer. Best synthesis conditions are determined, and the produced anion exchanger resin was tested with acid dye removal from synthetic solutions.

\section{Materials and Methodology}

\section{Materials}

- Waste cotton fiber was kindly supplied by Misr Spinning and Weaving Co., Mehalla ElKubra.

- GMA (Merck) [used after purification by vacuum distillation, using rotary evaporator at $100{ }^{\circ} \mathrm{C}$, in presence of $0.2 \%$ hydroquinone as inhibitor], sodium hydroxide (ADWIC, Egypt), sodium carbonate (ADWIC, Egypt), carbon disulfide $\left(\mathrm{CS}_{2}\right)$ (Panreac), ferrous sulfate (sd fine-chem limited), egyptol (ADWIC, Egypt), hydrogen peroxide (ADWIC, Egypt), nitric acid (ADWIC, Egypt), hydroquinone (WINLAB), acetone (ADWIC, Egypt), hydrochloric acid (sd fine-chem limited), triethylamine (ADWIC, Egypt) are used analytical grade, and C.I. Acid Black 194 (synthesia, a.s.) of commercial grade. Figure 1 represents the chemical structure of C.I. Acid black dye 194.<smiles>O=[N+]([O-])c1ccc2c(/N=N/c3c(O)ccc4ccccc34)c(O)cc([S+](=O)(=O)[O-])c2c1</smiles>

Fig. 1. Structure of C.I. Acid black dye 194. 


\section{Methodology}

The adopted methodology can be described in three basic processes viz:

- Synthesis of the target product.

- Analysis and characterization.

- Testing the optimized product as dye adsorbent.

\section{Synthesis of the anion exchange resin}

Scouring [19]

Waste cotton sample was first purified by scouring in a solution containing $\mathrm{NaOH}(5 \mathrm{gm} / 1)$, $\mathrm{Na}_{2} \mathrm{CO}_{3}(3 \mathrm{gm} / \mathrm{l})$ and egyptol as wetting agent $(2 \mathrm{gm} / \mathrm{l})$, during 60 mins., at $90{ }^{\circ} \mathrm{C}$ within $\mathrm{pH}$ ranging from $12-14$ and 1:40 material-to-liquor ratio, to eliminate any fatty acids or grease adhered on the cotton fibers during processing.

Thiocarbonation of Cotton sample [20]

The reaction was conducted in a $30 \mathrm{~mL}$ stoppered glass vessel using a thermo-controlled shaking water bath (Julabo SW21) at $30{ }^{\circ} \mathrm{C}$ constant temperature. The treated cotton sample was added to a thiocarbonation solution composed of $1 \% \%_{(w / v)} \mathrm{NaOH}, 1 \%_{(\mathrm{v} / \mathrm{v})} \mathrm{CS}_{2}$ and $0.2 \%_{(\mathrm{w} / \mathrm{v})}$ egyptol as wetting agent to increase the reaction efficiency. The contents of the vessel, with a material to liquor ratio equivalent to $1: 25$, were continuously shaken throughout the thiocarbonation reaction for $2 \mathrm{hrs}$., after which, the cotton sample was pressed out using a padder. The cotton fabric in this form will be referred to as cellulose thiocarbonate.

Graf polymerization: The thiocarbonated cotton sample $(0.5 \mathrm{~g})$ was pretreated by immersion in $0.1 \%$ ferrous sulphate solution in a $30 \mathrm{ml}$ glass bottle kept at room temperature for 30 mins. After impregnation, the sample was washed, rapidly, with distilled water and pressed out until 7-8 times of its original weight. The graft copolymerization reaction was also performed in a $30 \mathrm{ml}$ glass bottle, immersed into the controlled thermostatic shaking water bath, fixed at the required operating temperature $\left(30-70{ }^{\circ} \mathrm{C}\right)$, where the pressed sample was mixed with the polymerization emulsion consisting of $0.2 \%$ (w/v) egyptol (as emulsifying agent), and specific concentrations of GMA monomer and $\mathrm{H}_{2} \mathrm{O}_{2}$ (as initiator) at definite $\mathrm{pH}$, with a predetermined water to material liquor ratio. After the desired reaction time (10-60 $\mathrm{min}$ ), few drops of $250 \mathrm{ppm}$ hydroquinone (in methanol) were immediately added to the reaction flask while cooling in an ice bath for terminating the polymerization reaction. The grafted product was taken out, thoroughly washed with distilled water, and then impregnated in acetone overnight, to extract any traces of the homopolymer and the unreacted monomer that may be physically adhered to the product fibers. The final copolymer was dried at $40{ }^{\circ} \mathrm{C}$ using air dryer to a constant weight.

\section{Aminization: \\ i. Preparation of triethylammonium chloride (TEAC) [21]}

The preparation of the desired amine was carried out in a three neck round flask placed in an ice bath. A condenser, through which the rode of a mechanical stirrer passes for mixing the content, was mounted into the middle flask neck. The two others were connected to: - a separating funnel joined with a rubber tube expanded to the bottom of the solution and, -a pH measuring probe. A known amount of trimethylamine and approximately an equivalent amount of concentrated hydrochloric acid were charged into the flask and the funnel respectively. The acid was allowed to pass to the bottom of the flask dropwize under stirring; the final $\mathrm{pH}$ was around 5.

\section{ii. Aminization procedure}

$1 \mathrm{~g}$ of previously optimized Cellulosepoly(glycidyl-methacrylate) graft copolymer (CPGMA) with known epoxy content was placed in a $30 \mathrm{ml}$ quick-fit glass bottle. The aqueous solution of TEAC with specified concentration and liquid to material liquor ratio is then added to the sample and the solution $\mathrm{pH}$ was adjusted to the desired value. The bottle with its components is then introduced into a thermostatic shaking water bath at specific temperature and the reaction is allowed to proceed for a definite time. The sample was then pressed out using the padder, washed with a dilute solution of sodium carbonate to remove any adhered amount of hydrochloric acid then washed with distilled water until filtrate neutrality and finally dried in air oven drier at 60 ${ }^{\circ} \mathrm{C}$ for 60 mins. The extent of aminization reactions was expressed as nitrogen percent (N\%).

\section{Analysis and characterization}

Analysis: -The procedure adopted for the determination of free epoxy-ring content in the synthesized CPGMA was essentially based on Schöniger flask test [22].

-The extent of grafting with GMA is recorded by weight difference, while that of the aminization of aminated waste cotton is monitored through the nitrogen content by embracing the Kjeldahl method [23] using vapodest 20s.

-For grafting parameters determination, the Egypt.J.Chem. 62, No. 3 (2019) 
filtrates from both polymerization and extraction processes were evaporated in a known weighted round flask using a rotary vacuum evaporator at $100{ }^{\circ} \mathrm{C}$ to eliminate the solvent and any amount of the unreacted monomer, thus the following parameters could be determined:

Polymer add-on $\%=\left[\left(\mathrm{w}_{1}-\mathrm{w}_{\mathrm{o}}\right) / \mathrm{w}_{\mathrm{o}}\right] \times 100$

Graft yield $\%=\left[\left(\mathrm{w}_{2}-\mathrm{w}_{\mathrm{o}}\right) / \mathrm{w}_{\mathrm{o}}\right] \times 100$

Total conversion $\%=\left[\left(\mathrm{w}_{3}-\mathrm{w}_{4}\right) / \mathrm{w}_{3}\right] \times 100$

Grafting efficiency $\%=\left[\left(\mathrm{w}_{2}-\mathrm{w}_{\mathrm{o}}\right) / \mathrm{w}_{5}\right] \times 100$

Where $\mathrm{w}_{0}, \mathrm{w}_{1}, \mathrm{w}_{2}, \mathrm{w}_{3}$ and $\mathrm{w}_{4}$ and $\mathrm{w}_{5}$ are the weight of initial cotton sample, grafted sample without extraction, grafted sample with extraction, initial monomer charged, and total amount of grafted and homopolymer respectively.

-Finally, the aminization conversion and efficiency percentwere evaluated, via:

Aminization conversion: $\left[\left(\mathrm{y}_{\mathrm{o}}-\mathrm{y}_{1}\right) / \mathrm{y}_{\mathrm{o}}\right] \mathrm{x} 100$

Aminization efficiency (mol \%): $\left[\left(\mathrm{y}_{0}-\mathrm{y}_{1}\right) / \mathrm{y}_{2}\right]$ x 100

Where $\mathrm{y}_{0}, \mathrm{y}_{1}$ and $\mathrm{y}_{2}$ are the initial amount of charged amine, un-reacted amine and epoxy content respectively.

Characterization: - Analysis by Fourier transform infra-red spectrophotometer (FT-IR) was carried out for native waste cotton, grafted cotton and aminated grafted cotton using a JASCO FT/IR6100- in the range from 400 to $4000 \mathrm{~cm}^{-1}$.

- Thermal gravimetric analysis (TGA) was conducted for the three samples by thermal analyses SDTQ 600 apparatusat rate of $10{ }^{\circ} \mathrm{C} / \mathrm{min}$ in $\mathrm{N}_{2}$ atmosphere.

- Surface area measurements based on
Brunauer-Emmett-Teller (BET) and BarrettJoyner-Halenda $(\mathrm{BJH})$ theories, namely, surface area $\left(\mathrm{m}^{2} / \mathrm{g}\right)$, total pore volume $(\mathrm{cc} / \mathrm{g})$, average pore radius $(\mathrm{nm})$ and the complete isotherm of native, grafted, and the aminated cotton samples were evaluated using St 2 on NOVA touch 4LX [s/n:17016062702] device.

Testing the prepared product as dye adsorbent

Dye sorption trial of the amino-functionalized cellulose-poly (glycidyl methacrylate) graft copolymer (AM-CPGMA), synthesized at optimum reaction conditions, was performed by immersion of $0.1 \mathrm{~g}$ sample in $50 \mathrm{ml}$ acid black dye solution of $300 \mathrm{ppm}$ initial concentration. The mixture was kept at room temperature under shaking at different $\mathrm{pH}$ and time values. After the required time, the adsorbent sample was filtered and the filtrate was analyzed for rejected dye concentration on a Cary Series UV-Vis spectrophotometer at $575 \mathrm{~nm}$ maximum wavelength.

Tentative reactions mechanism

Cellulosic cotton fibers react with carbon disulphide in presence of sodium hydroxide to yield sodium cellulose thiocarbonate, according to the following equation:

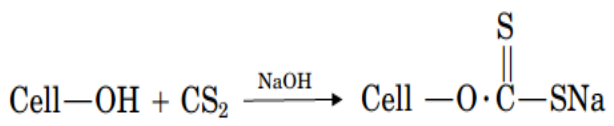

When treating the formed thiocarbonate with ferrous sulfate solution, two molecules of the former will react with one molecule of the latter forming ferrous cellulose thiocarbonate, which in turn act as a reducing agent or as a co-initiator with hydrogen peroxide to yield hydroxyl radicals (Fenton reaction), viz:

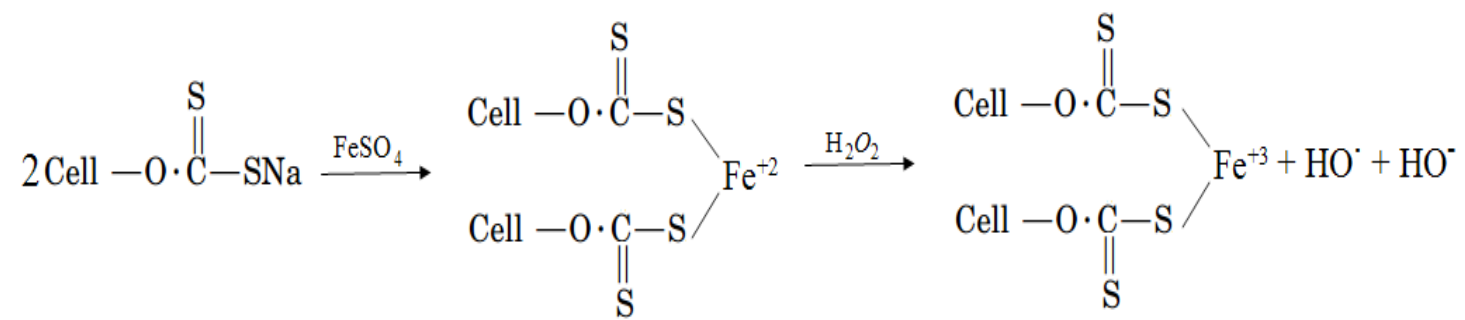

In the presence of a GMA monomer, the cellulose macroradical encourages graft polymerization of the monomer on the cellulose backbone to yield cellulose poly(glycidyl methacrylate) graft copolymer, as follows: 


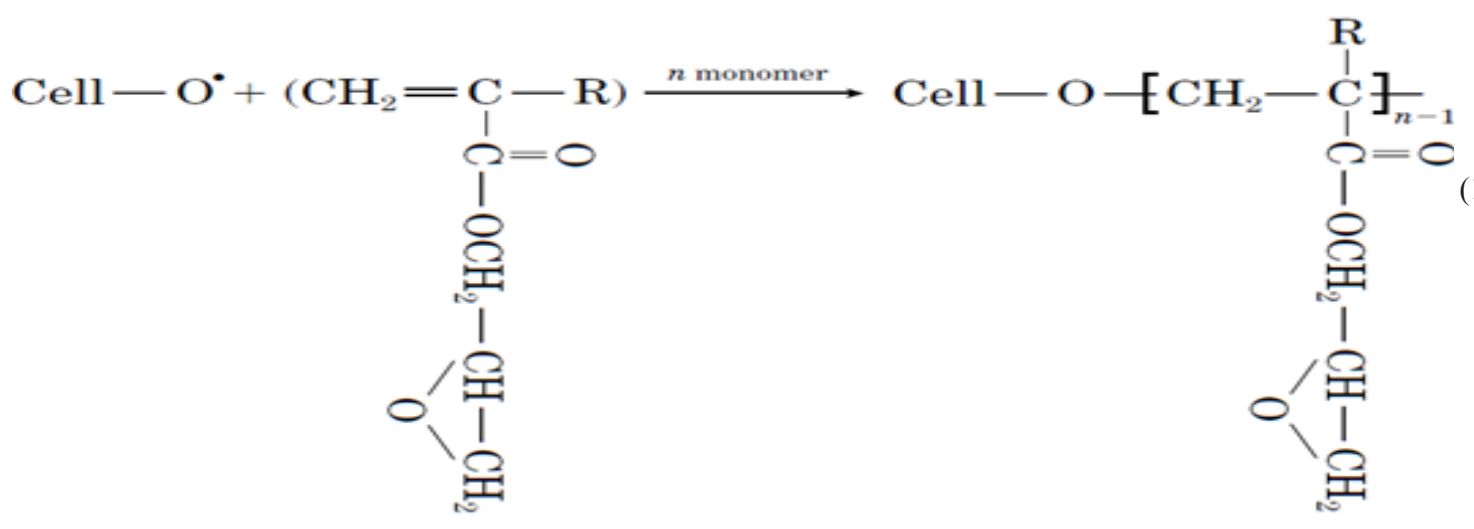

This copolymer (Cell-g-PGMA) can be functionalized and converted to anion exchanger by the reaction of its epoxy groups with triethylammonium chloride to yield cationized ammonium groups with counter chlorine ions as depicted in the following reaction:

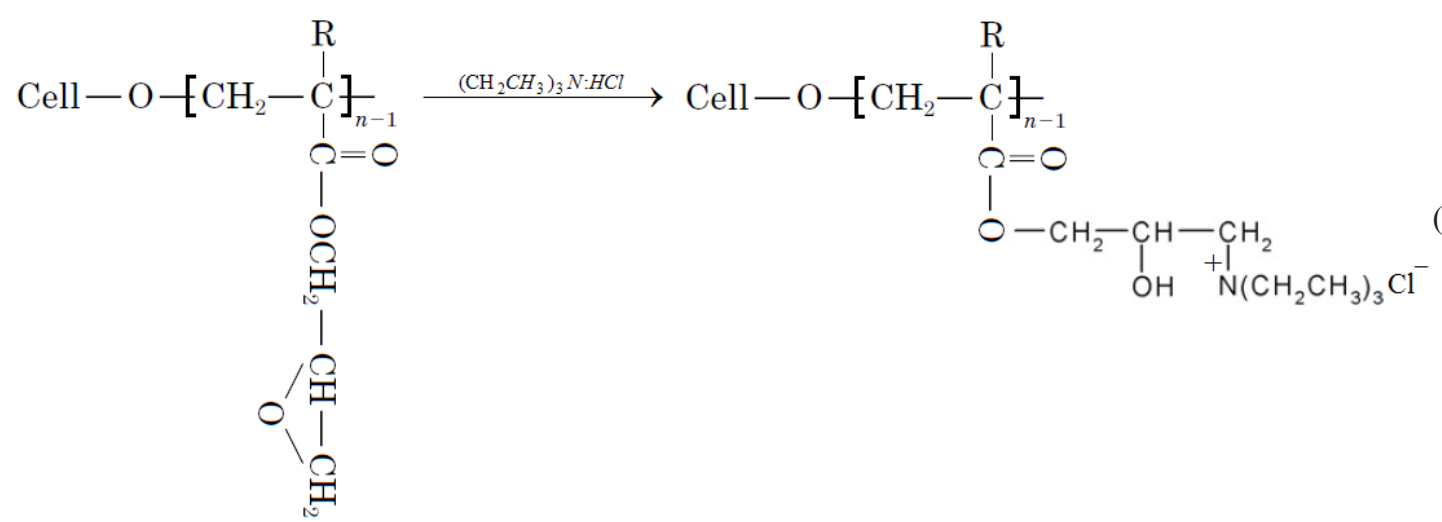

\section{Results and Discussion}

\section{Grafting results}

Effect of polymerization time

Figure 2 illustrates the dependence of the graft yield \% and the epoxy content on time, by remaining constant other parameters.

As observed, the graft yield increases by increasing the polymerization time and reaches a maximum value (188\%) at 30 mins. By prolonging the duration above this value, no noticeable change occurs in the graft yield, this is may be contributed to the depletion of the monomer, in addition to the reduction of active sites number on backbone of the cellulose available for the grafting as reaction proceed [17]. The graft yield \% reaches to its maximum value after only 30 minutes due to the high rate and efficiency of the used ferrous cellulose thiocarbonatehydrogen peroxide co-initiator, which in turn cease the realization of free homopolymer. Also the high conversion rate and reactivity of GMA as mentioned before was the main reason for the high rate of graft polymerization.
The epoxy content increases also by increasing the time and reaches its maximum value (1.76 mmol) after 20 mins. Afterward, it declines slightly to a constant degree as the time proceeds, probably because of conversion of certain amount of the epoxy groups formed into hydroxyl groups, since the reaction is carried out in aqueous medium and under the shown conditions, which in turn increase the reaction of epoxy groups with water or any impurities in the solution [24].

\section{Effect of monomer concentration}

A series of graft polymerization was performed in which monomer concentration was varied from $40-220 \%_{(\mathrm{w} / \mathrm{w})}$ relative to cotton sample, while other operating conditions were held constant. As shown in Fig. 3, graft yield \% increases by increasing monomer concentration in the investigated range. This is probably due to increasing the available amount of monomer at higher GMA concentrations in the vicinity of the cellulosic backbone where the latter is well known to be immovable in the reaction mixture [20].

Similarly, epoxy content increases by 


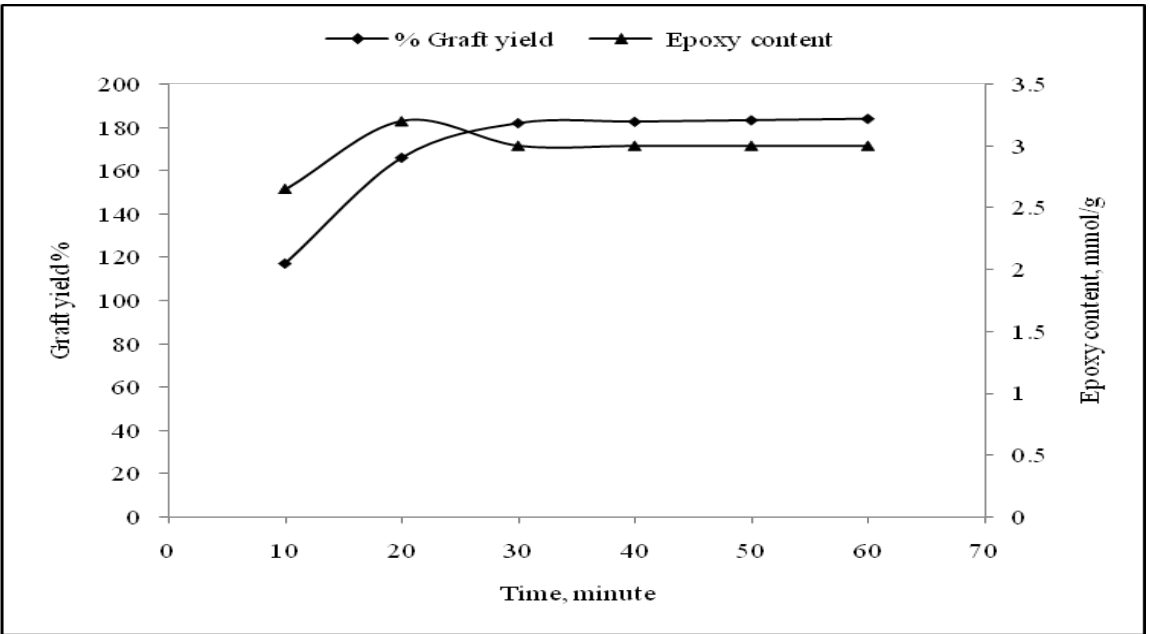

Fig. 2. Effect of time on graft yield and epoxy content, (Cotton sample $0.5 \mathrm{~g}$, GMA conc. $220 \%$ (w/w) relative to sample, $\mathrm{pH} \mathrm{3,} \mathrm{H}_{2} \mathrm{O}_{2} \quad 0.015 \%(\mathrm{w} / \mathrm{v})$, temperature $50{ }^{\circ} \mathrm{C}$, liquor ratio 25:1 $\left.(\mathrm{v} / \mathrm{w})\right)$.

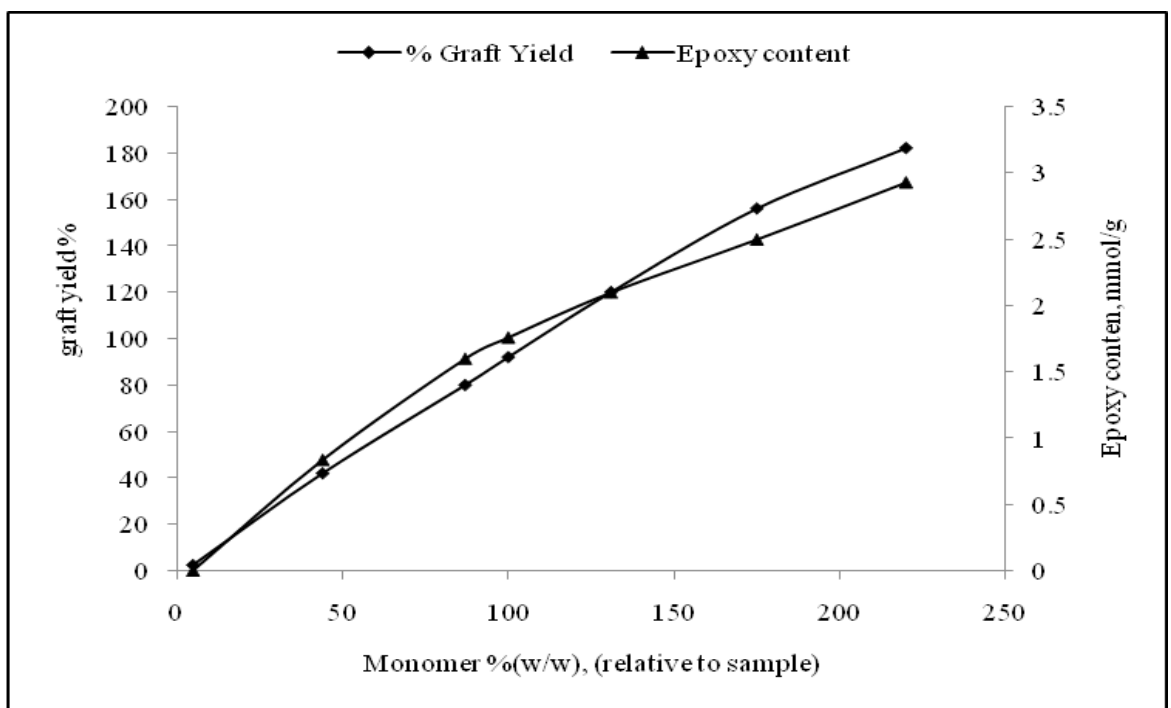

Fig. 3. Effect of monomer conc. on graft yield and epoxy content, (Cotton sample $0.5 \mathrm{~g}$, time $30 \mathrm{mins}$., $\mathrm{pH}_{3}, \mathrm{H}_{2} \mathrm{O}_{2}$ $0.015 \%_{(\mathrm{w} / \mathrm{v})}$, temperature $50{ }^{\circ} \mathrm{C}$, liquor ratio $\left.25: 1_{(\mathrm{v} / \mathrm{w})}\right)$.

increasing the monomer concentration but it is not relative to graft yield \% increase, since some epoxy ring may open up during grafting as mentioned above.

\section{Effect of $p H$}

In this section, the reaction medium is varied by operation at variable $\mathrm{pH}$ values from $2-6$. As illustrated in Fig. 4, the reaction occurs only in acidic medium and the graft yield \% increases by decreasing the $\mathrm{pH}$ and reaches its maximum value
$(188 \%)$ at $\mathrm{pH} 3$. This is due to the fact that, the efficiency of the initiation reaction is high at low $\mathrm{pH}$ values due to the presence of $\mathrm{Fe}^{2+}$ ions, which act as co-initiator enhancing the free radical graft polymerization onto cellulose considerably. It is recognized that, at low $\mathrm{pH}$ values (2-4), more $\mathrm{Fe}(\mathrm{OH})^{+}$ions is formed with higher activity than $\mathrm{Fe}^{2+}$ in Fenton oxidation. In contrast, at $\mathrm{pH}>4.0$, ferrous ions are unstable and can form ferric ions which have a susceptibility to produce complexes of ferric hydroxo. Further, by rising the $\mathrm{pH}$ value 
above 9.0, these complexes can form $[\mathrm{Fe}(\mathrm{OH})]^{-4}$. In addition, in basic solution, $\mathrm{H}_{2} \mathrm{O}_{2}$ is unstable and may decompose to oxygen and water and lose the ability of oxidation [25].

As shown also, the epoxy content $\%$ decreases

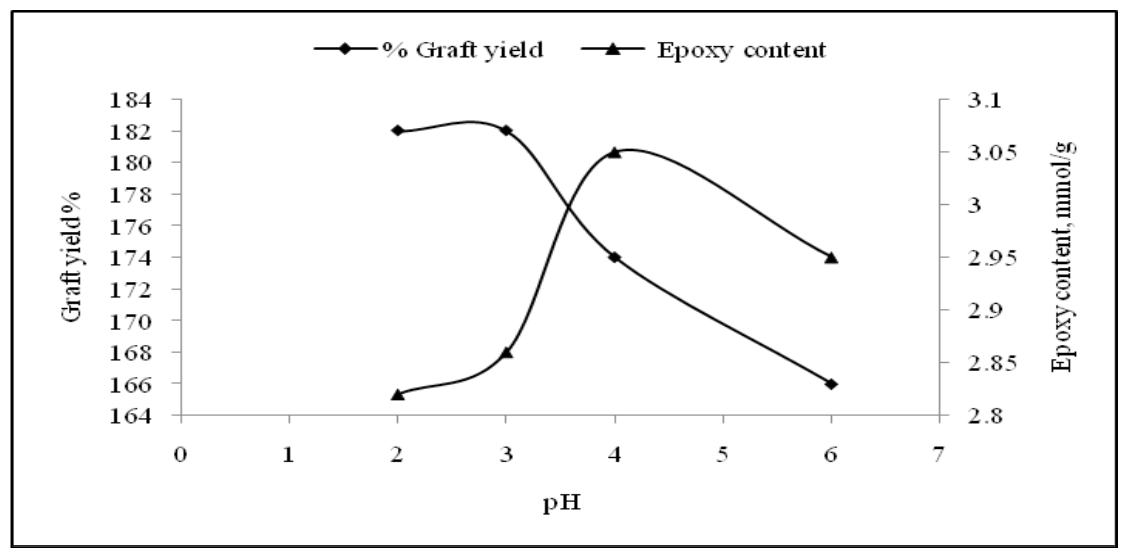

Fig. 4. Effect of $\mathrm{pH}$ on graft yield and epoxy content, (Cotton sample $0.5 \mathrm{~g}$, GMA conc. $220 \%_{(\mathrm{w} / \mathrm{w})}$, time 30 mins., $\mathrm{H}_{2} \mathrm{O}_{2} \quad 0.015 \%{ }_{(\mathrm{w} / \mathrm{v})}$, temperature $50{ }^{\circ} \mathrm{C}$, liquor ratio $\left.25: 1_{(\mathrm{v} / \mathrm{w})}\right)$.

by decreasing $\mathrm{pH}$, as a result of the increasing conversion of epoxy groups into hydroxyl groups by reacting with protons under the reaction conditions.

\section{Effect of $\mathrm{H}_{2} \mathrm{O}_{2}$ concentration}

As illustrated in Fig. 5, variation of $\mathrm{H}_{2} \mathrm{O}_{2}$ concentration results in a significant increase in the graft yield $\%$ up to $0.01 \%{ }_{(w / v)}$, followed by a slight increase and reaches its maximum value at $0.015 \%_{(\mathrm{w} / \mathrm{v})}$ then levels off. The regular rise at low $\mathrm{H}_{2} \mathrm{O}_{2}$ concentrations is expected due to the increase in ${ }^{\circ} \mathrm{OH}$ free radicals. The minor growth observed within $0.01 \%_{(\mathrm{w} / \mathrm{v})}$ to $0.015 \%_{(\mathrm{w} / \mathrm{v})}$ is may be caused by the consumption of some of the $\cdot \mathrm{OH}$ radicals by $\mathrm{Fe}^{2+}$ built in cellulose into $\mathrm{Fe}^{+3}$ affecting the grafting reactions. Further increase in $\mathrm{H}_{2} \mathrm{O}_{2}$ concentration results in more radicals produced, which probably combine to promote termination of the growing grafted chains. And due to the thiocarbonation step, the $\mathrm{HO}^{*}$ are formed in the vicinity of the hydroxyl groups of cellulose chains not in the solution, this leads to the total monomer conversion is mainly grafted GMA not homopolymer and this also decreases the possibilities of termination [20].

Moreover, Fig. 4 indicates that the epoxy content increases by increasing the $\mathrm{H}_{2} \mathrm{O}_{2} \%$ and reaches its maximum value at $0.015 \%_{(\mathrm{w} / \mathrm{v})}$, and

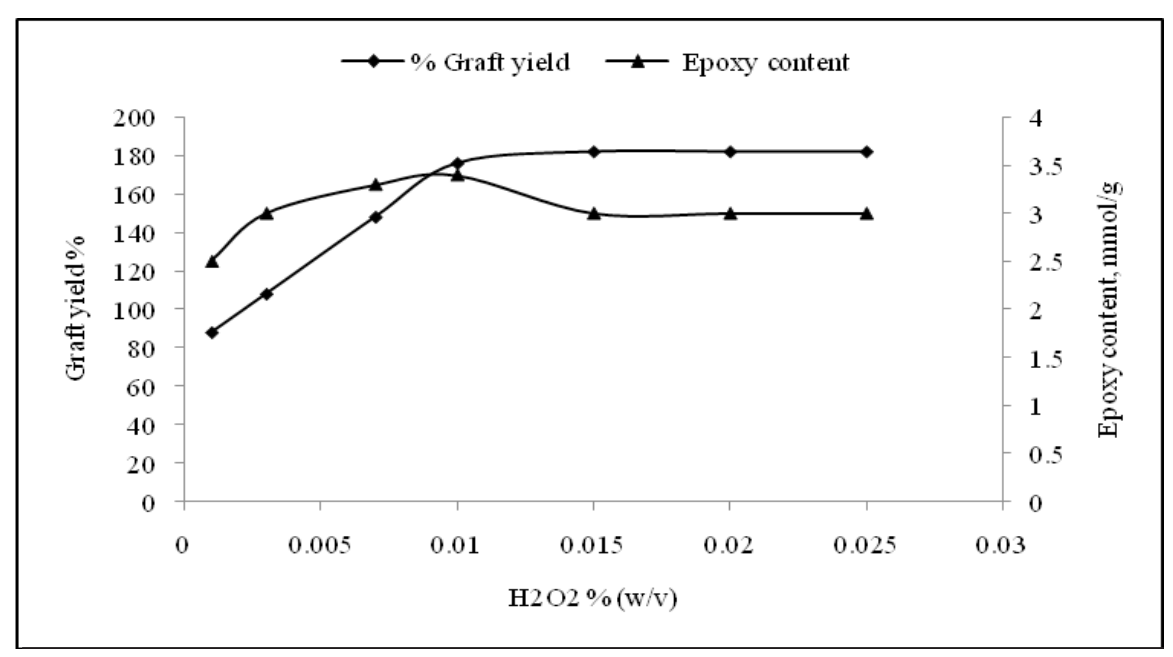

Fig. 5. Effect of $\mathrm{H}_{2} \mathrm{O}_{2}$ conc. on graft yield and epoxy content, (Cotton sample $0.5 \mathrm{~g}$, GMA conc. $220 \%$ (w/w) , time 30 mins., $\mathrm{pH} 3$, temperature $50{ }^{\circ} \mathrm{C}$, liquor ratio $\left.25: 1_{(\mathrm{v} / \mathrm{w})}\right)$. 
then it starts to decrease as the $\mathrm{H}_{2} \mathrm{O}_{2} \%$ increases above this value, due to increasing conversion of the epoxy groups into hydroxyl groups by the increased amount of the formed $\mathrm{HO}^{-}$under the shown conditions.

\section{Effect of temperature}

As shown from Fig. 6, graft yield \% increases by increasing the grafting temperature and reaches its maximum value at $60{ }^{\circ} \mathrm{C}$ and no noticeable change occurs in the graft yield \% by increasing the temperature above this value.

This is rather a direct consequence of improvement of the solubility of the monomer and its diffusion from the solution to the fiber and enhancement of the rate of initiation and propagation [20]. Beyond this value, raising the temperature may result in rapid termination; thereby initiate reducing the reaction rate.

In contrast, the epoxy content decreases by increasing the temperature from $30-70{ }^{\circ} \mathrm{C}$, due to increasing the conversion of the epoxy groups into hydroxyl groups by rising the temperature above $30^{\circ} \mathrm{C}$.

\section{Effect of liquor ratio}

Figure 7 shows that the graft yield \% increases with increasing the liquor ratio and attained a maximum at 1:25, where by increasing the liquor

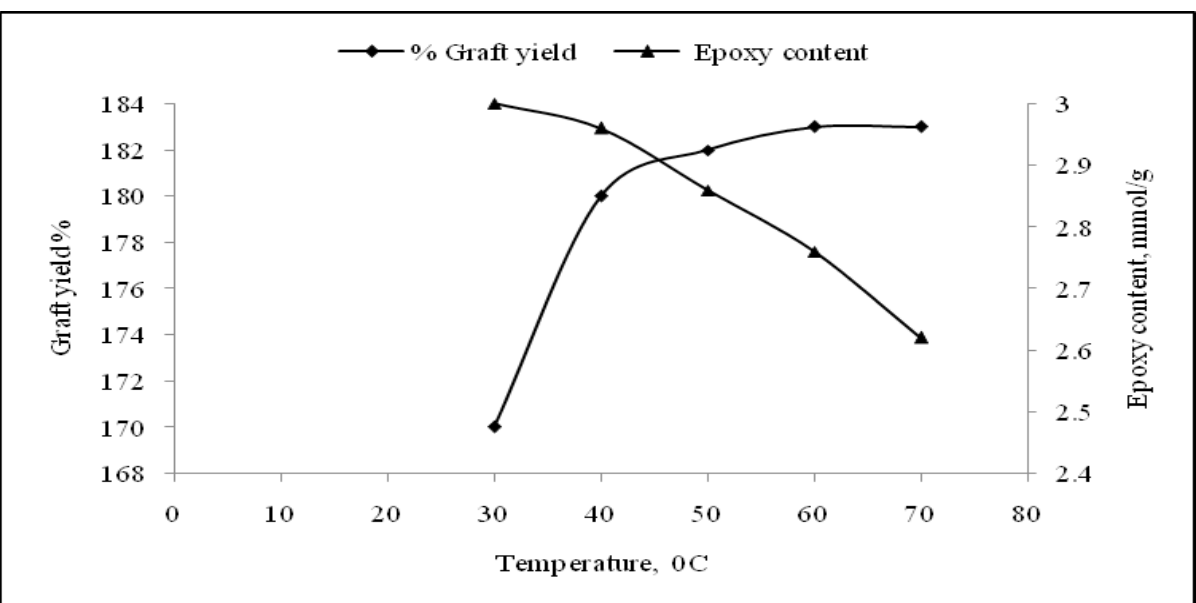

Fig. 6. Effect of temperature on graft yield and epoxy content,(Cotton sample $0.5 \mathrm{~g}$, GMA conc. $220 \%_{(\mathrm{w} / \mathrm{w})}$, time 30 mins., pH 3, $\mathrm{H}_{2} \mathrm{O}_{2} 0.015 \% \%_{(\mathrm{w} / \mathrm{v})}$, liquor ratio 25:1 $\left.1_{(\mathrm{v} / \mathrm{w})}\right)$.

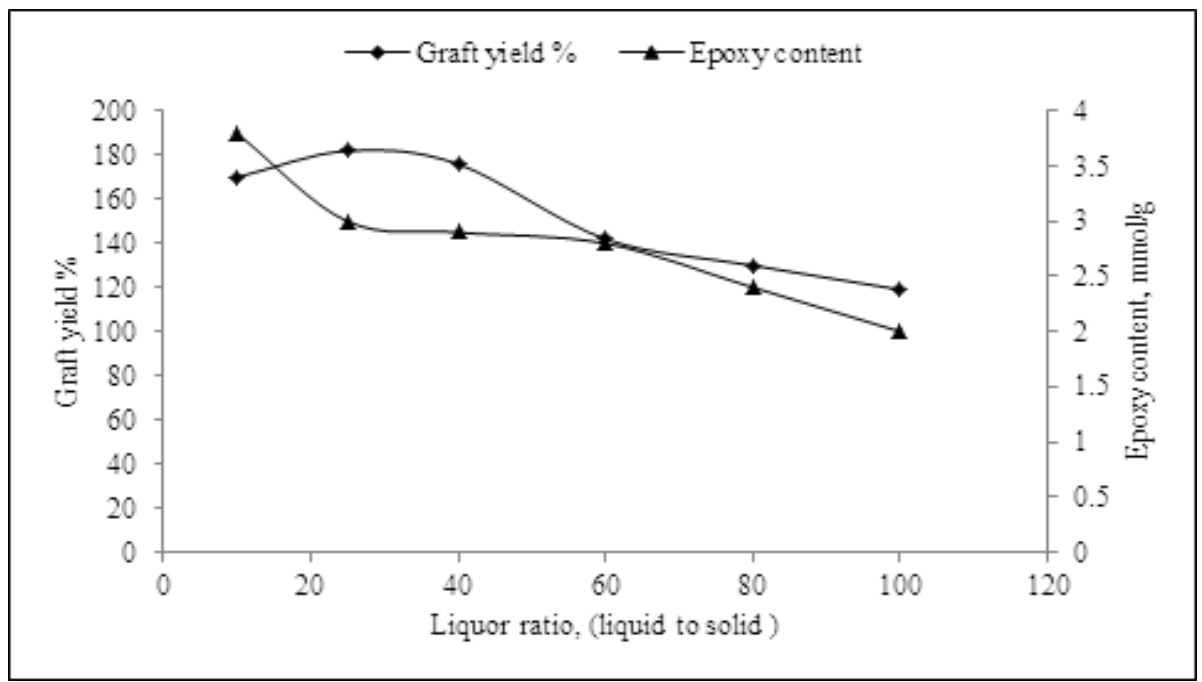

Fig. 7. Effect of liquor ratio on graft yield and epoxy content, (Cotton sample 0.5g, GMA conc. $220 \%_{(\mathrm{w} / \mathrm{w})}$, time 30 mins., $\mathrm{pH} \mathrm{3}, \mathrm{H}_{2} \mathrm{O}_{2} 0.015 \%(\mathrm{w} / \mathrm{v})$, temperature $\left.50{ }^{\circ} \mathrm{C}\right)$. 
ratio above this value, the graft yield \% decreases, This can be attributed to the insufficient amount of the solvent required for transportation molecular collisions, at low material to liquor ratio. While at high material to liquor ratio, graft yield \% decreases because of dilution and lower molecular collision among the polymerization reactants [26].

Oppositely, the epoxy content is a maximum at 10:1 liquid to material liquor ratio and decreases by increasing the liquor ratio above this value.

TABLE 1. Grafting evaluation results.

\section{Optimum grafting conditions}

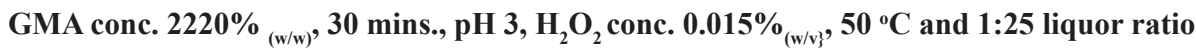

\begin{tabular}{cccc}
\hline Total conversion \% & Grafting efficiency $\%$ & Graft yield $\%$ & Polymer add-on $\%$ \\
98 & 88 & 188 & 200 \\
\hline
\end{tabular}

This is because of the increased conversion of epoxy groups into hydroxyl groups by increasing the amount of water under the operating conditions

\section{Grafting evaluation results}

At optimum operating conditions obtained, the evaluation of the graft polymerization process parameters results of the final graft sample was tabulated in Table 1.

\section{Aminization results}

Effect of temperature

It is noticed from Fig. 8 that, raising the reaction temperature is accompanied by a sharp increase in the conversion of epoxy groups to amines within temperature range of $50{ }^{\circ} \mathrm{C}$ to 80 ${ }^{\circ} \mathrm{C}$. This is ascribed to the satisfactory importance of temperature on:

a) Copolymer swelling and enhancement of epoxy groups availabilities.

b) Baeyer strain increasing in the epoxy rings, and its breaking liability increasing [27].

c) Reactants kinetic energy increasing and their ability to collide.

d) Supplying the system with the required energy that overcome the reaction activation energy barrier.

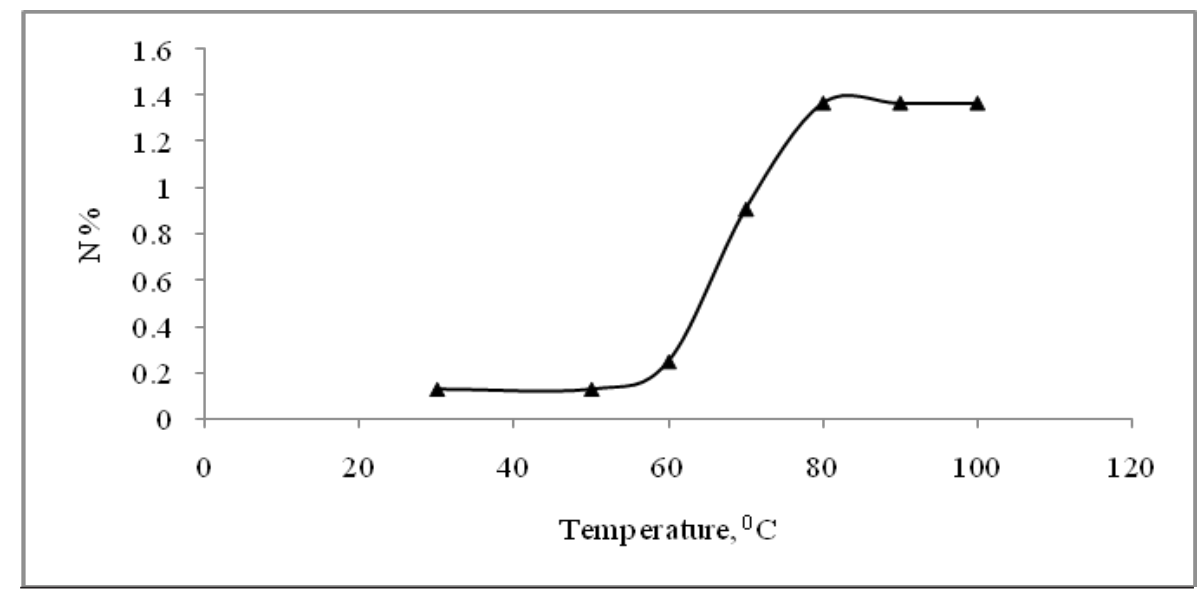

Fig. 8. Effect of temperature on \% nitrogen content. CPGMA $1 \mathrm{~g}$ (epoxy content $1.76 \mathrm{mmol} / \mathrm{g}$ ), time $60 \mathrm{mins}$. , pH 7 , liquor ratio $12.5: 1_{(\mathrm{v} / \mathrm{w})}$, amine conc. $18 \%_{(\mathrm{w} / \mathrm{v})}$.

The observed flatness over $80{ }^{\circ} \mathrm{C}$ probably indicates that both aminization and side reactions (i.e., crosslinking and hydrolysis) happen instantaneously during the operating time with nearly constant ratio. It is also noticed that by increasing the temperature from $30-50{ }^{\circ} \mathrm{C}$, there was no change occurred in the nitrogen percent.
This may be interpreted as the extent of ring opening has a critical temperature at which the reaction proceeds rapidly.

\section{Effect of time}

Figure 9 shows that, with respect to reaction time, initially, the extent of conversion proceeds 


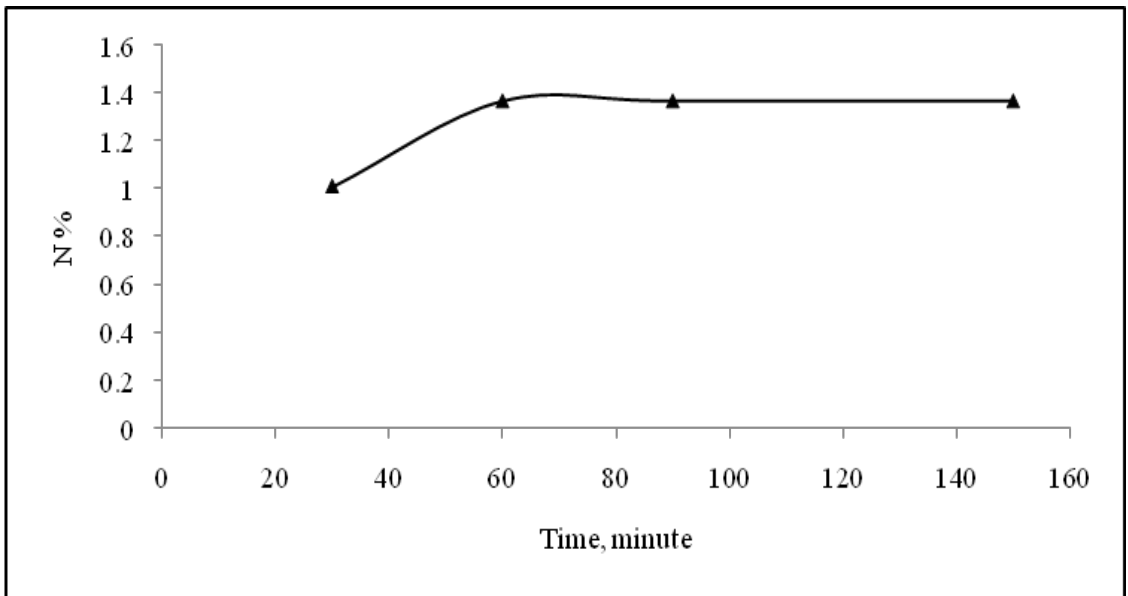

Fig. 9. Effect of time on $\%$ nitrogen content, CPGMA $1 \mathrm{~g}$ (epoxy content $1.76 \mathrm{mmol} / \mathrm{g}$ ), temperature $80{ }^{\circ} \mathrm{C}$, $\mathrm{pH} 7$, liquor ratio 12.5: $1_{(\mathrm{v} / \mathrm{w})}$, amine conc. $18 \%_{(\mathrm{w} / \mathrm{v})}$.

at a fast rate up to 60 mins., between 60 and 90 mins., it decreases with time by a slower rate, then levels off over 90 mins.

This indicates that the aminization reaction ceased after $1 \mathrm{hr}$ and the side reactions, i.e., crosslinking and hydrolysis, predominate thereafter [28].

\section{Effect of $p H$}

The initial $\mathrm{pH}$ was 7 and as shown from Fig. 10, the $\mathrm{N} \%$ decreases with the decrease of $\mathrm{pH}$ by addition of hydrochloric acid. This may be explained as with addition of hydrochloric

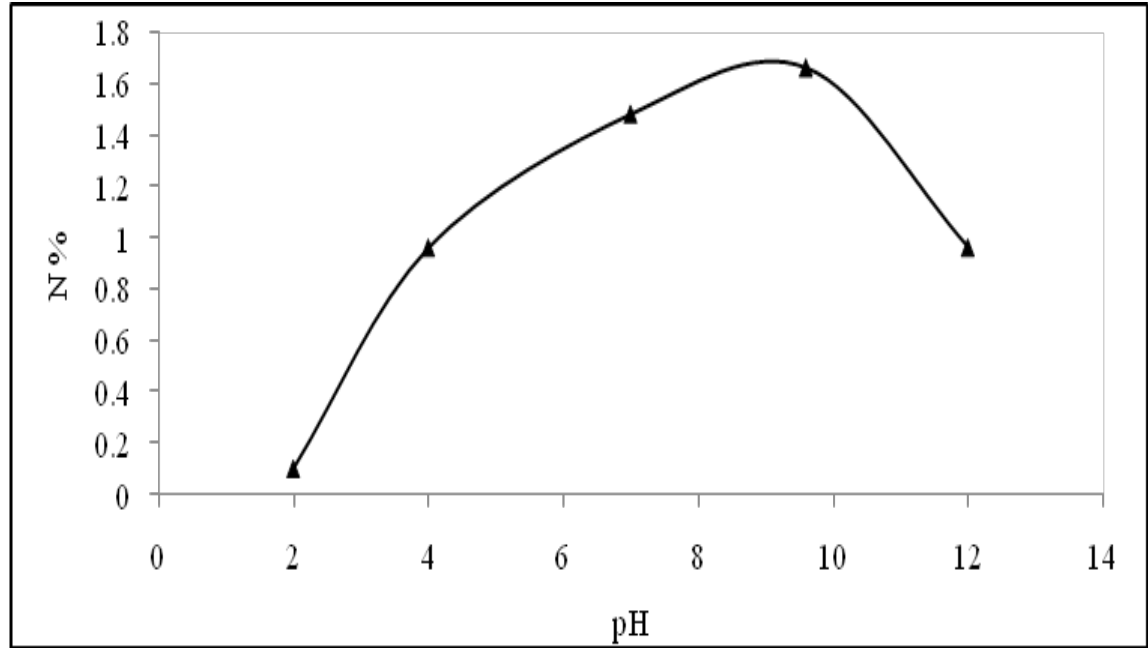

Fig. 10. Effect of pH on nitrogen content \%, CPGMA $1 \mathrm{~g}$ (epoxy content $1.76 \mathrm{mmol} / \mathrm{g}$ ), temperature $80{ }^{\circ} \mathrm{C}$, time 60 mins., liquor ratio $12.5: 1_{(\mathrm{v} / \mathrm{w})}$, amine conc. $18 \%_{(\mathrm{w} / \mathrm{v})}$.

acid the reaction of $\mathrm{Cl}^{-}$predominates. Increase of $\mathrm{pH}$ from 7 is accompanied by an increase in nitrogen percent till it attained a maximum at $\mathrm{pH}$ 9.6. Further increase in $\mathrm{pH}$ is accompanied by a decrease in the nitrogen percent. This may be due to the catalytic effect of protons on thisreaction [29].

\section{Effect of liquor ratio}

Figure 11 shows that the N\% was a maximum at 12.5:1 liquor ratio. There was a considerable decrease in the nitrogen percent by increasing the liquor ratio above this value. This may be due to the decrease of epoxy groups concentration on increasing the liquor ratio [30]. 


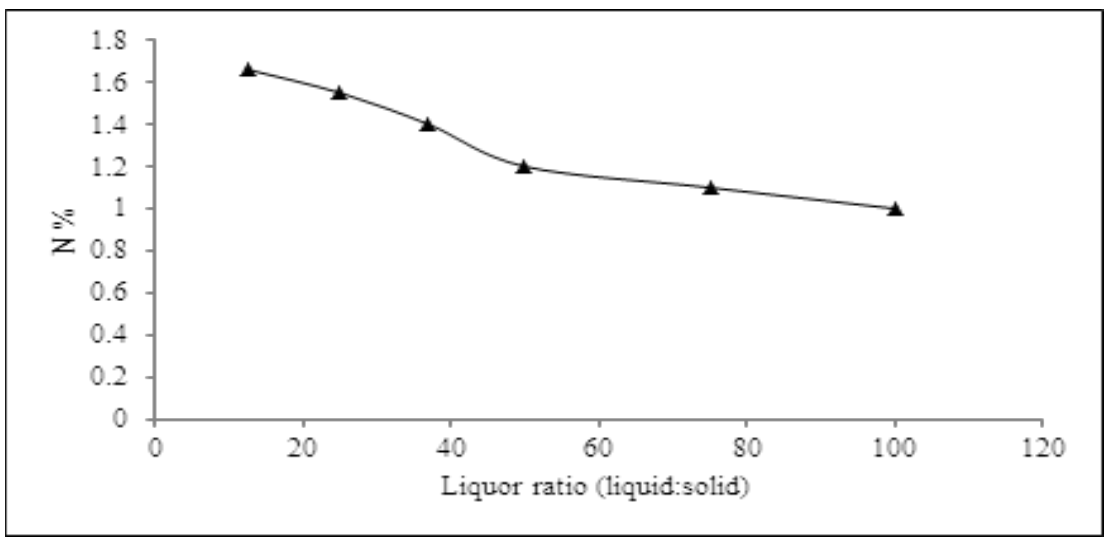

Fig. 11. Effect of liquor ratio on nitrogen content \%, CPGMA $1 \mathrm{~g}$ (epoxy content $1.76 \mathrm{mmol} / \mathrm{g}$ ), temperature $80{ }^{\circ} \mathrm{C}$, time 60 mins., pH 9.6, amine conc. $18 \%_{(w / v)}$. ratio

Effect of the Aminating agent/Epoxy molar

Variation of the amount of amine to that of epoxy content was investigated and the results are illustrated in Fig. 12. The N\% increases by increasing the aminating agent/ epoxy molar ratio up to $8: 1$ and then levels off. This may be explained by the consumption of most of the initial epoxy content, at low aminating agent/ epoxy molar ratios, in its reaction with water. Increasing the amine concentration is escorted by a significant

increase in the amination extents and with a slight decrease in the undesired reactions extent, i.e. hydrolysis and crosslinking. The reduction in the undesired reactions extent and increasing amine concentration may be associated with: i) amine exerted a competition to react with CPGMA, and ii) repulsive forces increasing between cellulosepoly(glycidyl methacrylate) graft copolymer (CPGMA)chains for crosslinking induced by the positive charges acquired on aminization [31].

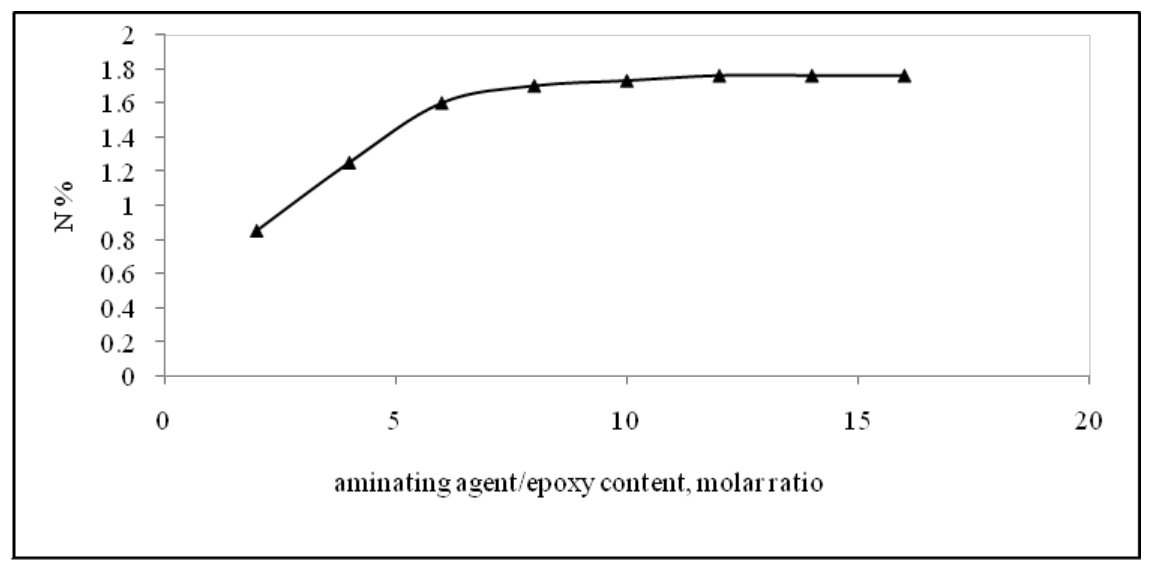

Fig. 12. Effect of amine conc. on nitrogen content \%, CPGMA $1 \mathrm{~g}$ (epoxy content $1.76 \mathrm{mmol} / \mathrm{g}$, temperature $80^{\circ} \mathrm{C}$, time 60 mins., pH 9.6, liquor ratio 12.5: $1_{(\mathrm{v} / \mathrm{w})}$

\section{Aminization evaluation results}

At optimum conditions, the aminization parameters are determined [equations (4-5)] and the results are depicted in Table 2. The total conversion was between $8-10 \%$ and the amination $\%$ was between $83-86 \%$. However, the total conversion $\%$ is low, the aminated sample could be filtered and washed with distilled water only, then the nitrogen content of the produced filtrate was determined and the concentration or the molar ratio of this filtrate was adjusted to use it in another amination reaction. 
TABLE 2. Aminization evaluation results.

Optimum aminization conditions

Aminization agent/epoxy content molar ratio 8:1, 60 mins., $80{ }^{\circ} \mathrm{C}$, pH 10, liquor ratio 12.5:1.

Total conversion $\%$

$8-10$

Aminization efficiency \%

86

\section{Characterization}

FT-IR spectroscopy

Figure 12 illustrates the FT-IR spectra of the native, grafted and aminated cotton. Figure 12a shows the FT-IR spectrum of the waste cotton showing a broad intense absorption band at $3428 \mathrm{~cm}^{-1}$ due to $\mathrm{O}-\mathrm{H}$ groups. The IR spectrum of the cellulose-poly(glycidyl methacrylate) graft copolymer (CPGMA) (Fig. 12b) shows the absorption bands at $1729 \mathrm{~cm}^{-1}$ arising from $\mathrm{C}=\mathrm{O}$ stretching vibration, also new bands were observed at 906,850 and $752 \mathrm{~cm}^{-1}$ attributed to epoxy ring. After aminization with triethylammonium chloride, a new absorption bands at 1076 and $655 \mathrm{~cm}^{-1}$ (Fig. 12c) were observed which is respectively characteristic for asymmetric and symmetric stretching vibration of $\mathrm{C}-\mathrm{N}^{+}$in the quaternary ammonium group [32]. The adsorption bands characteristic for remaining epoxy ring still appears after the aminization. The existence of these characteristic bands approves the grafting of cotton with GMA and chemical

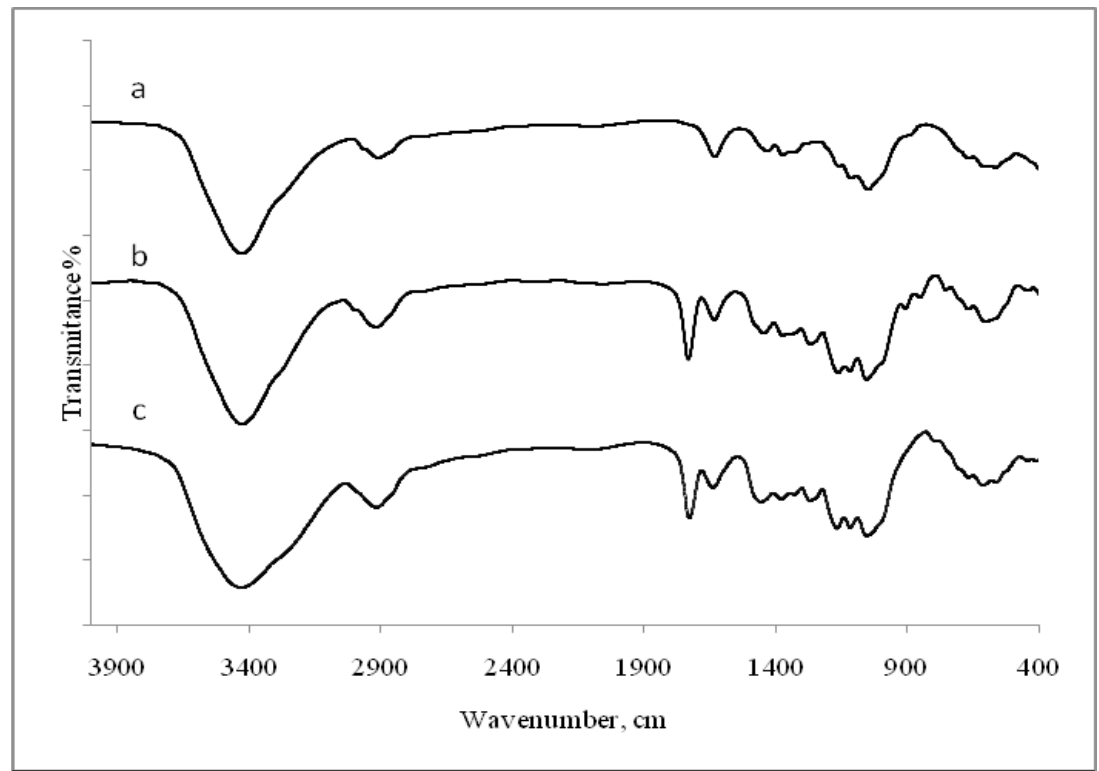

Fig. 13. FT-IR spectrum of untreated waste cotton (a), grafted cotton (b) and the aminated cotton (c).

functionalization of the GMA-grafted cotton with triethylammonium chloride.

Thermal gravimetric analysis (TGA)

4.3.2. Thermal gravimetric analysis (TGA)

Thermal stability and degree of hydrophilicity of native (Fig. 13a), grafted (Fig. 13b) and the aminated cotton (Fig. 13c) were investigated by thermal gravimetric analysis (TGA) and differential thermal gravimetric analysis (DTG). The ratio of water content in cotton fabric was $10 \%$, which decreases to $5 \%$ after grafting, then increases to $11 \%$ after aminization with triethylammonium chloride; this indicates that the degree of hydrophilicity decreases with grafting due to the hydrophobic nature of GMA, whereas the degree of hydrophilicity increases after aminization due to the introduction of hydrophilic amino group.

The TGA and DTG curves of native cotton are characterized by three different temperature zones. In the initial stage of decomposition (30$263{ }^{\circ} \mathrm{C}$ ), almost $10 \%$ of the mass is lost because 
of water release. In the second stage $\left(263-393^{\circ} \mathrm{C}\right)$, about $90 \%$ of the initial dry weight is lost as a result of the breaking of glucosidic and carbon- carbon bonds to form a series of hydrocarbons, alcohols, aldehydes, acids, and others, followed by decomposition of these compounds into

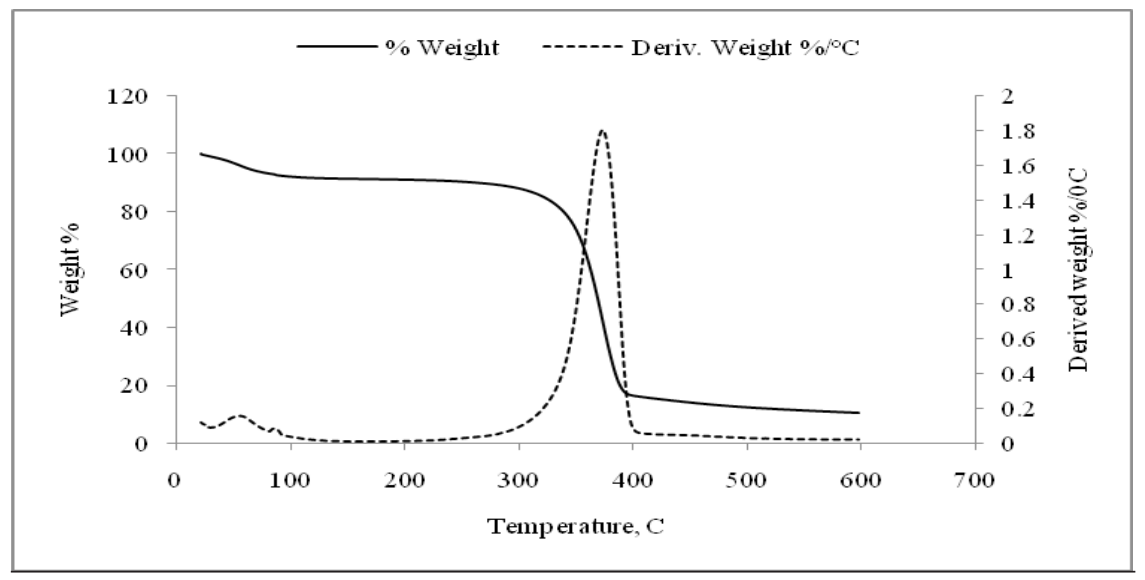

Fig. 14a. TGA curves of native cotton.

large amounts of volatiles and solid char [33]. From the derived weight calculations the highest decomposition percent in the second stage was at $370^{\circ} \mathrm{C}$.

The TGA and DTG curves of the grafted cotton show the decomposition and weight loss to occur in four different stages. In the first stage (47-202 ${ }^{\circ} \mathrm{C}$ ) about $5 \%$ weight loss was observed, due to water release. In the second stage of decomposition $\left(202-265^{\circ} \mathrm{C}\right.$ ) about $12 \%$ of the initial weight was lost, because of the pyrolytic of GMA polymer that was grafted onto the cellulose [33]. In the third stage $\left(265-390{ }^{\circ} \mathrm{C}\right)$ the total weight loss was about $72 \%$ as a result of splitting of the cellulose structure and main-chain scission. In the final stage $\left(390-450{ }^{\circ} \mathrm{C}\right)$ the total

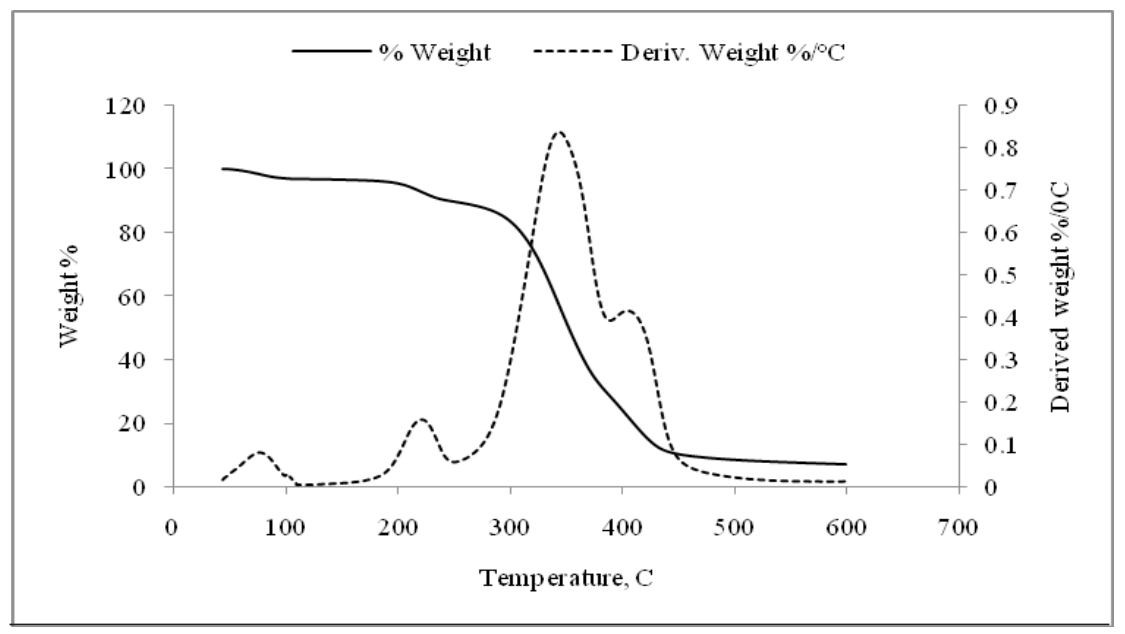

Fig. 14b. TGA curves of grafted cotton.

weight loss was about $93 \%$ due to decomposition of large amounts of volatiles and solid char. Derived weight calculations showed that the highest decomposition percent were at 214, 337 and $394{ }^{\circ} \mathrm{C}$ for the second, third and fourth stage respectively.

The TGA and DTG curves of the aminated cotton show the decomposition and weight loss to occur in four different stages. In the first stage $\left(42.5-210^{\circ} \mathrm{C}\right)$ about $11 \%$ weight loss was 
observed, due to water evaporation. In the second stage $\left(210-300{ }^{\circ} \mathrm{C}\right)$ about $36 \%$ weight loss was detected, which may be due to the pyrolytic of GMA polymer that was grafted onto the cellulose and removal of amino groups [17]. In the third stage of decomposition $\left(300-390{ }^{\circ} \mathrm{C}\right)$ about $69 \%$ of the weight was lost, because of splitting of the cellulose structure and main-chain scission.

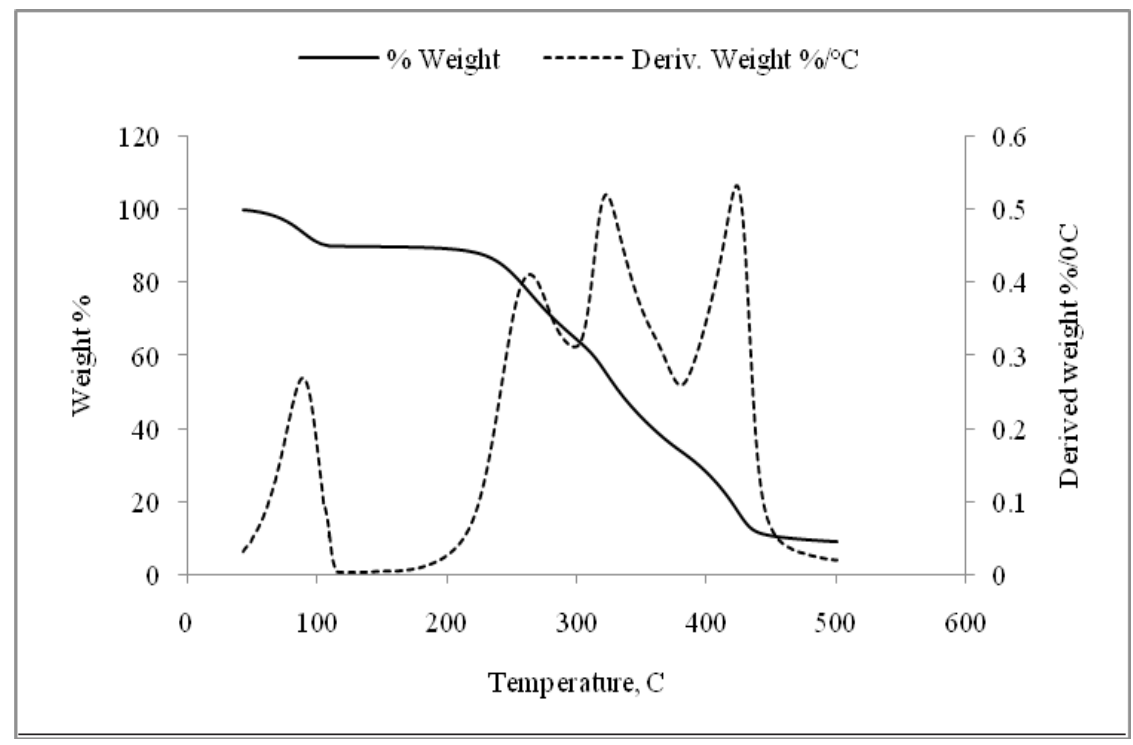

Fig. 14c. TGA curves of the aminated cotton.

In the final stage $\left(390-450{ }^{\circ} \mathrm{C}\right)$ the total weight loss was about $91 \%$ because of the formation of large amounts of volatiles and solid char from the decomposed cellulose units. The highest decomposition percent were at 256.6, 318.6 and $420{ }^{\circ} \mathrm{C}$ for the second, third and fourth stage respectively.

Although amino-functionalized cellulosepoly(glycidyl methacrylate) graft copolymer (AM-CPGMA) was found to be thermally less stable than cellulose, AM-CPGMA is stable up to $282^{\circ} \mathrm{C}$, and as such, thermal stability will not pose any problems in its practical applications.

Surface area measurement (PET\&BJH)

The surface area of the native and aminated cotton was measured, and the results are depicted in Table 3.

Table 3 demonstrates that the surface area and total pore volume of the native cotton increases

TABLE 3. Surface area, average pore radius and total pore volume of the native, grafted and aminated cotton.

\begin{tabular}{cccc}
\hline Sample & Surface area $\left(\mathbf{m}^{2} / \mathbf{g}\right)$ & Average pore radius $(\mathbf{n m})$ & Total pore volume $(\mathbf{c c} / \mathbf{g})$ \\
\hline Native cotton & 20.2658 & $1.9236 \mathrm{e}^{+000}$ & $1.9492 \mathrm{e}^{-002}$ \\
Aminated cotton & 45.4314 & $9.5748 \mathrm{e}^{-001}$ & $2.1750 \mathrm{e}^{-002}$ \\
\hline
\end{tabular}

after aminization, while the average pore radius decreases. This result may be interpreted as after aminization and grinding of the aminated cotton, the surface area of cotton particles increases, these results in average pore radius decrease and total pore volume increase.

\section{Adsorption test results}

Effect of $p H$

As shown in Fig. 14, the $\mathrm{pH}$ has no effect on the adsorption capacity, $\mathrm{q}(\mathrm{mg} / \mathrm{g})$ and the percentage removal within the whole $\mathrm{pH}$ range studied. The uniform sorption capacity at the equilibrium 


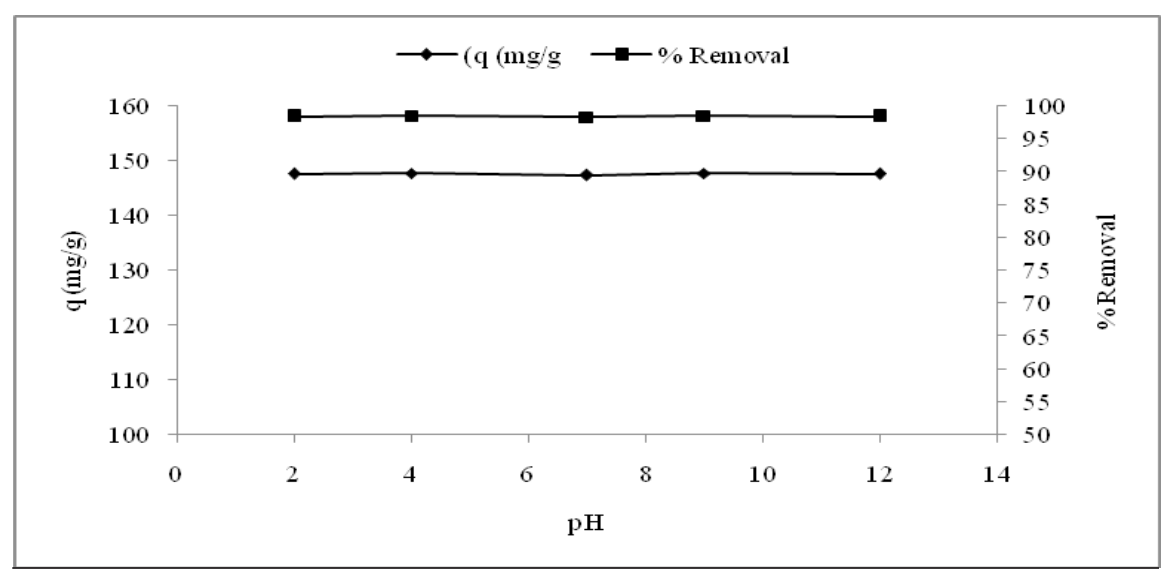

Fig. 15. Effect of $\mathrm{pH}$ on the adsorption and the \% removal of acid black dye, (Sample $0.1 \mathrm{~g}(1.7 \mathrm{~N} \%)$, time $48 \mathrm{hrs}$., temperature $25^{\circ} \mathrm{C}$, initial dye conc. $300 \mathrm{ppm}$ ).

was attained because the quaternary ammonium groups are ionic in both basic and acidic medium $[34,35]$. At the adsorption operating conditions stated in Fig. 14 the removal percent of the dye is almost $100 \%$ after $48 \mathrm{hrs}$.

\section{Effect of time}

Figure 15 illustrates that the adsorption capacity and the percentage removal increases as the time increase and up to approximately 30 mins. Beyond this value, it tends to level off. It

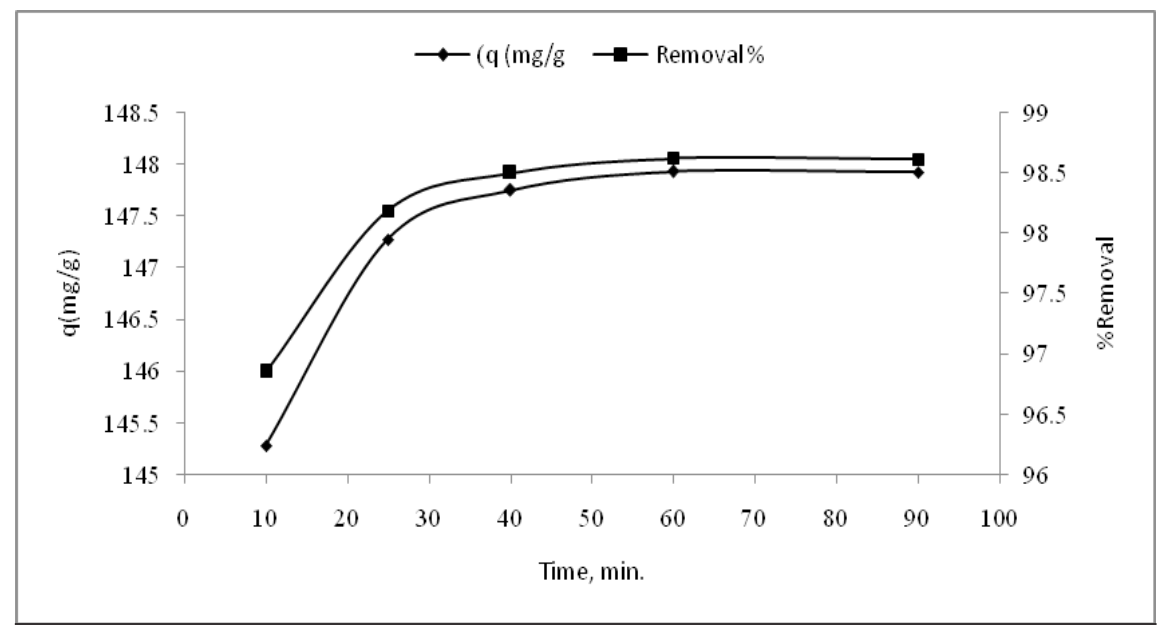

Fig. 16. Effect of time on the adsorption and the \% removal of acid black dye, (Sample $0.1 \mathrm{~g}(1.7 \mathrm{N \%})$, pH 9, temperature $25^{\circ} \mathrm{C}$, initial dye conc. $300 \mathrm{ppm}$ ).

is also noticed that the adsorption capacity and the removal \% have a high value approaching the maximum, and this is attributed to the high reactivity of the cationized ammonium group toward the anionic dyes [36].

\section{Conclusion}

Synthesis of the amino-functionalized cellulose-poly(glycidyl methacrylate) graft copolymer (AM-CPGMA) based on waste cotton fibers was achieved by graft polymerization of GMA onto cotton fabric using a ferrous cellulose thiocarbonate-hydrogen peroxide redox system as a co-initiator with subsequent aminization. The best grafting results giving epoxy content equivalent to $1.76 \mathrm{mmol} / \mathrm{g}$ were at 30 mins., $\mathrm{pH}$ $3, \mathrm{H}_{2} \mathrm{O}_{2}$ conc. $0.015 \%_{(\mathrm{w} / \mathrm{v})}, 50{ }^{\circ} \mathrm{C}$ and $25: 1$ liquor ratio, while the highest $\mathrm{N} \%(1.76 \%)$ was at 60 mins., $80^{\circ} \mathrm{C}, \mathrm{pH}$ 9.6, 12.5:1 liquor ratio and 8:1 aminating agent/epoxy content molar ratio. The 
synthesized cellulose anion exchanger (CellAE) was characterized by means of the FT-IR, thermal gravimetric (TGA) and surface area measurement using PET \& BJH analysis. Surface area measurement indicates that the surface area $\left(\mathrm{m}^{2} / \mathrm{g}\right)$ and total pore volume $(\mathrm{cc} / \mathrm{g})$ increased from 20.2658 and $1.9492 \mathrm{e}^{-002}$ to 45.4314 and $2.1750 \mathrm{e}^{-002}$ respectively with regard to native cotton and the prepared anion exchanger, and this increased the adsorption capacity. The removal of acid black dye was tested by the prepared anion exchanger and exhibited an increase from 23.83 $\mathrm{mg} / \mathrm{g}$ for cotton to a maximum value of 147.27 $\mathrm{mg} / \mathrm{g}$ for the prepared anion exchanger after 30 mins., at any $\mathrm{pH}$ value.

\section{References}

1. Ibrahim, S., Fatimah, I., Ang, H.M. and Wang, S., Adsorption of anionic dyes in aqueous solution using chemically modified barley straw. Water Sci. Technol., 62, 1177-1182 (2010).

2. Ayhan, D., Agricultural based activated carbons for the removal of dyes from aqueous solutions: a review. Journal of Hazardous Materials, 167, 1-9 (2009).

3. Aksu, Z., Application of biosorption for the removal of organic pollutants: A review. Process Biochem., 40, 997-1026 (2005).

4. Shen, D., Fan, J., Zhou, W., Gao, B., Yue, Q. and Kang, Q., Adsorption kinetics and isotherm of anionic dyes onto organobentonite from single and multisolutesystems. J. Hazard. Mater., 172, 99-107 (2009).

5. Do, J.S. and Chen, M.L., Decolourization of dyecontaining solutions by electrocoagualtion. J. of Appl. Electrochemistry, 24, 785-790 (1990).

6. El-Halwany, M., Study of adsorption isotherms and kinetic models for methylene blue adsorption on activated carbon developed from Egyptian rice hull (Part II). Desalination, 250, 208-213 (2010).

7. Lee, J.W., Choi S.-P., Thiruvenkatachari, R., Shim, W.-G. and Moon, H., Evaluation of the performance of adsorption and coagulation processes for the maximum removal of reactive dyes. J. Dyes Pigm., 69, 196-203 (2006).

8. Fan, L., Zhou, Y., Yang, W., Chen, G. and

Egypt.J.Chem. 62, No. 3 (2019)
Yang, F., Electrochemical degradation of aqueous solution of Amarnathazo dye on ACF under potentiostaticmodel. Dyes Pigment, 76, 440-446 (2008).

9. Lorenc-Grabowsk, E. and Gryglewic, G., Adsorption characteristics of Congo red on coal-based mesoporous activated carbon. Dyes Pigment, 74, 34-40 (2007).

10. Neelavannan, M.G., Revathi, M. and Ahmed Basha, C., Photocatalytic and electro-chemical combined treatment of textile wastewater. $J$ Hazard Mater., 149, 371-378 (2007).

11. Sohrabi, M.R. and Ghavami, M., Photocatalytic degradation of Direct Red 23 dye using UV/ TiO2, Effect of operational parameters. $J$ Hazard Mater, 153, 1235-1239 (2008).

12. Lodha, B. and Chaudhari, S., Optimization of Fenton biological treatment scheme for the treatment of aqueous dye solution. J Hazard Mater., 148, 459-466 (2008).

13. Kapdan, I.K. andKargi, F., Simultaneous bio degradation and adsorption of textile dye stuff in an activated sludge unit. Process Bio Chem, 37, 973-981 (2002).

14. Waranusantigul, P., Pokethitiyook, P., Kruatrachue, M.andUpatham, E.S., Kinetics of basic dye methylene blue biosorption by giant duck week Spirodelapolyrrhiza. Environ. Poll., 385, 92 (2003).

15. Roy, D., Semsarilar, M., Guthriea, T.J. and Perrier, S., Cellulose modification by polymer grafting: A review. Chem. Soc. Rev., 38, 20462064 (2009).

16. Hokkanen, S., Bhatnagar, A. and Sillanpaa, M., A review on modification methods to cellulose-based adsorbents to improve adsorption capacity. Water Research, 91, 156173 (2016).

17. Sokker, H.H., Badawy S.M., Zayed, E.M., Nour Eldien, F.A. and Farag, A.M., Radiationinduced grafting of glycidyl methacrylate onto cotton fabric waste and its modification for anchoring hazardous wastes from their solutions. Journal of Hazardous Materials, 168, 137-144 (2009).

18. Anirudhan, T. S., Jalajamony, S. and Divya, L., Efficiency of amine-modified poly(glycidyl methacrylate)-grafted cellulose in the removal and recovery of vanadium(v) from aqueous 
solutions. Ind. Eng. Chem. Res., 48, 21182124 (2009).

19. Samudrika Wijayapala, U.G, Dharmasena, D.K.A.S., Bandara, D.M.N, Chathuranga, M.A.I. and Rajapakshe, K.S., Development of a new scouring methodology for the textile industry In: National Engineering Conference, 2013, 19TH Eru Symposium, Faculty of Engineering, University of Moratuwa, Sri Lank, 38-42 (2013).

20. Hebeish, A., Waly, A., Abdel-Mohdy, F. A. and Aly, A. S., synthesis and characterization of cellulose ion exchangers. i. polymerization of glycidyl methacrylate, dimethylaminoethyl methacrylate, and acrylic acid with cotton cellulose using thiocarbonate- $\mathrm{H}_{2} \mathrm{O}_{2}$ redox system. Journal of Applied Polymer Science, 66, 1029-1037 (1997).

21. Harland, C.E., Ion Exchange. Theory and Practice. The Royal Society of Chemistry, Cambridge (1994).

22. Abou-Zeid, N. Y., Waly, A., El-Alfy, E. A. and Hebeish, A., Fe ${ }^{+2}$-thioureadioxide$\mathrm{H}_{2} \mathrm{O}_{2}$ induced polymerization of glycidyl methacrylate and its mixtures with acrylamide, acrylonitrile, butylmethacrylate, or styrene with cotton fabric. Journal of Applied Polymer Science, 27, 2105-2117 (1982).

23. Cole, J.O., Parks, C.R., A semimicro-kjeldahl destillation apparatus, Ind. Eng. Chem. Anal. Ed., 18 (1), 1-82 (1946).

24. Bonollo, S., Lanari, D. and Vaccaro, L., Ringopening of epoxides in water. Eur. J. Org. Chem., 2587-2598 (2011).

25. Shaobin Wang., A Comparative study of Fenton and Fenton-like reaction kinetics in decolourisation of wastewater. Dyes and Pigments, 76, 714-720 (2008).

26. Shakila, P., Rekha, K.R., Vijayalakshmi K. and Sudh, P. N., Synthesis, characterization and optimisation of carboxymethyl chitosan graft gylcidyl methacrylate copolymer. International Journal of Applied and Advanced Scientific Research, 1(2), 2456-3080 (2016).

27. Reutov, O., Theoretical Principles of Organic Chemistry, Ed. Engl., Chap. 4, Mir, Moscow, p. 242 (1967).
28. Kubota, H. and Ujita, S., Reactivity of clycidyl-methacrylate-grafted cellulose prepared by means of photografting. Journal of Applied Polymer Science, 56, 25-31(1995).

29. Mika, T. F., In Epoxy Resins, Chemistry and Technology, Eds., C. A. May, Y. Tanaka, Chap. 4, Dekker, New York, 239 (1973).

30. Abou-Shosha, M.H. and Ibrahim, N.A., Reaction of cellulose-poly(glycidyl methacrylate) with methylamine. Die Angewandte Makromolekulare Chemie, 152, 93-106(1987).

31. Khalil, M. I., Wally, A., Kantouch, A., AboShosha, M. H., Preparation of ion-exchange celluloses. I. Anion exchange celluloses, Journal of Applied Polymer Science, 38, 313322 (1989).

32. Migahed, M.A., Shabana, M.M., Fadda, A.A., Tamer, A.A. and Negm, N. A., Synthesis of some quaternary ammonium gemini surfactants and evaluation of their performance as corrosion inhibitors for carbon steel in oil well formation water containing sulfide ions. The Royal Society of Chemistry Advances, 5, 104480-104492 (2015).

33. Donia, A.M., Atia, A.A., El-Boraey, H. and Mabrouk, D.H., Uptake studies of copper(ii) on glycidyl methacrylate chelating resin containing $\mathrm{fe}_{2} \mathrm{O}_{3}$ particles. Sep. Purif. Technol., 49, 64-70 (2006).

34. Wawrzkiewicz, M. and Hubicki, Z., Ion Exchange - Studies and Applications, 61-63 (2015).

35. Constantina, M., Asmarandeia, I., Harabagiua, V., Ghimicia, L., Ascenzib, P., and Fundueanua, G., Removal of anionic dyes from aqueous solutions by an ion-exchanger based on pullulanmicrospheres. Carbohydrate Polymers, 9, 74- 84 (2013).

36. Liu, L., Gao, Z., Su, X., Chen, X., Jiang, L., and Yao, J., Adsorption Removal of Dyes from Single and Binary Solutions Using a Cellulosebased Bioadsorbent. ACS Sustainable Chem. Eng., 3(3), 432-442 (2015).

(Received 26/8/2018; accepted 3/10/2018) 
تحضير وتوصيف مبادل ايوني مبني على عوادم الالياف القطنية لإزالة الصبفات من

المخلفات السائلها

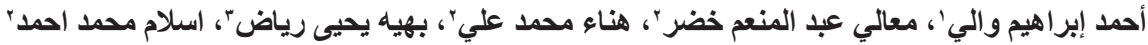

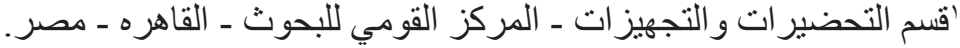

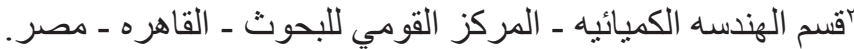

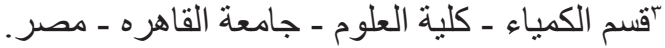

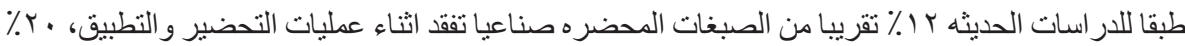

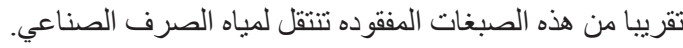

تمثل هذه الصبغات خطر كبير على الكائنات الحيه، لذا فقد تم تطوير العديد من الطرق لاز التهائه التها من المخلفات

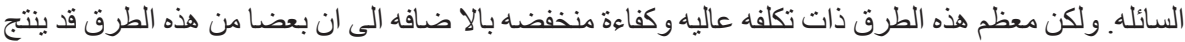

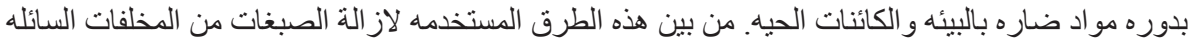

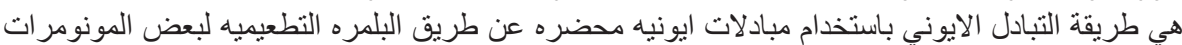

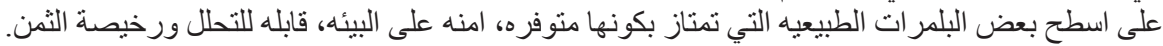
نتيجة لما سبق ففي العمل الحالي تم تحضير مبادل ايوني عن طريق البلمره التطعيميه لاحد المونمرات مع العو ادم القطنيه الناتجه اثناء مر احل صناعة النسيج المختلفه ثم تفعيله بادخال (glycidyl methacrylate) أحد مجمو عات الأمين.

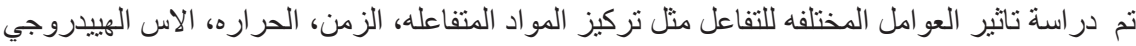

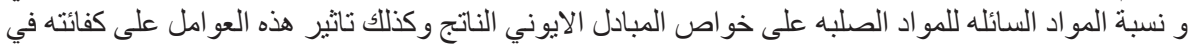

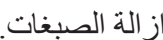

تم توصيف المنتج بالطرق الكميائيه مثل تحديد محتوى مجموعات الابوكسي والمحتوى النيتروجيني

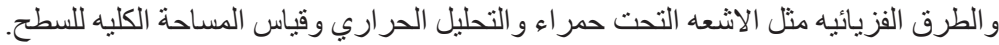

